https://doi.org/10.48009/1_iis_2010_497-506

\title{
USING DISCRETE EVENT SIMULATION TO EVALUATE THE BENEFITS OF RFID IN REDUCING TRAFFIC CONGESTION AND POLLUTION WHILE INCREASING STUDENT SAFETY IN RURAL OKLAHOMA SCHOOLS
}

\author{
Andrew A. Tiger, Union University, atiger@uu.edu \\ Ming-Shan Su, Southeastern Oklahoma State University, msu@ se.edu \\ Jane Hicks, Southeastern Oklahoma State University, gjhicks@ se.edu
}

\begin{abstract}
In this paper, we used discrete-event simulation to evaluate the benefits of RFID to improve an afterschool pickup process. The setting was a rural town in Oklahoma that has seen rapid growth. In addition to reducing pickup times by $49 \%$, demand management policies that convert spiky demand into level demand were shown to have benefits. Annual projected fuel savings due to less idling were estimated to be \$3,000. Similarly, an annual reduction of 60 thousand pounds of $\mathrm{CO} 2$ was estimated.
\end{abstract}

Although more difficult to quantify, our proposed RFID system is designed to increase safety and security. Further, the proposed system has the potential to reduce accidents by reducing parents' frustration due to waiting. Security is further increased because RFID systems assist in parent verification.

Keywords: RFID, Discrete Event Simulation, Simulation, Traffic Congestion

\section{INTRODUCTION}

\section{Impact of Rapid Population Growth on Traffic Systems}

Have you even been through the nightmare of waiting in a long line to pick up elementary school children? The typical process is stressful for the parents who must wait and for the frantically busy teachers and helpers, who must identify/verify the parents/guardians before allowing them to collect their kids.

As regional populations rapidly increase, traffic systems are one of the first and most visible systems that are negatively impacted. In the most extreme, accidents and loss of life occur. Most often, congestion and waiting create frustration, delays and reduced productivity. Additionally, congestion increases fuel consumption, carbon emissions, and pollution.

An elementary school in rural Oklahoma has been negatively impacted due to rapid population growth. Initially, morning drop-off and afternoon pickup policies created traffic congestion issues that potentially affected emergency vehicle access. The city stepped in and implemented a solution. However, solving the emergency vehicle access issue only shifted the congestion to another location.

Shifting of bottlenecks is a frequent occurrence when solutions are implemented directly on the real system without first evaluating a prototype or simulation. However, it is very difficult to evaluate solutions before implementation or to compare alternatives. Further, solving traffic flow problems is risky due to the required large investment to add infrastructure. A proven solution to system (re)design is discrete event simulation (DES). DES has been successfully used many times in the last 25 years; however, barriers still exist for its widespread use, especially in rural areas.

\section{Radio Frequency Identification (RFID) System}

An RFID system communicates over the air at a specific frequency, similar to any other radio communication. Its four major components are a tag/responder, a reader/transceiver, an antenna, and an air interface protocol. The main advantage of using RFID is that it does not require direct contact or line-of-sight scanning to gather information [19].

RFID systems are gaining ground in automatic identification systems and will eventually replace bar-coding in some applications. Applications range from inventory control systems, pay by mobile phones, automated toll road billings, animal tracking, passport identification, race timing, access control cards, parking lot optimization systems, and safety systems [16][20][26][30][32][37]. 
In this paper, we used discrete-event simulation to evaluate the benefits of RFID in reducing waiting during an afterschool pickup process. Initially, we review the literature on the environmental and safety impact of traffic congestion, the benefits of simulation and RFID. Next, we describe and model the current system, followed by providing validation of the model. We then simulate an economically feasible solution based on RFID that dramatically reduced traffic congestion.

\section{LITERATURE REVIEW}

\section{The Impact on Waiting on Safety and the Environment}

Ebbesen and Haney [6] performed an extensive field study and found that the probability of turning into traffic was directly related to the temporal distance of oncoming cars. Additionally, it was found that being forced to wait in line before turning substantially increased a driver's risk taking.

Federal tailpipe standards limit exhaust emissions of five pollutants [3] hydrocarbons, i.e., carbon dioxide, nitrogen oxides, carbon monoxide, particulate matter and formaldehyde. Except in concentrations higher than 5,000 parts per million vs. the fresh air norm of about $350 \mathrm{ppm}$, carbon dioxide is not toxic to humans [14]. Unfortunately, all other pollutants in tailpipe exhaust, whether regulated or not, are toxic to human health. Further, car exhaust does not just pollute the air outside buildings; it is sucked into buildings via air handlers. Other health hazards of exhaust that are not regulated include sulphur dioxide, suspended particles, benzene, and polycyclic hydrocarbons [23].

The toxins in car exhaust have the greatest impact on young people, old people, and people with respiratory problems, such as asthma, emphysema, and bronchitis. Children with respiratory problems are particularly at risk. According to the Center for Disease Control, the percentage of children with asthma jumped to $9 \%$ in 2005 from $3.6 \%$ in 1980 [22]. Although confounding variables make it difficult to ascribe exact causes for the increase, it is clear that the toxins in vehicle exhaust increase the number and level of asthma attacks and respiratory problems in children [27].

Many studies have found that vehicle emissions are associated with respiratory symptoms in children [7][25][31][34], including wheezing, medication use, school absences [13], and even reduced lung capacity [29]. In a 2004 study conducted at ten schools in

Volume XI, No. 1, 2010
California, researchers found that even relatively low concentrations of emission pollutants produced health problems in children, including respiratory symptoms, worsened asthma symptoms, and decreased lung function [18].

The health benefits of reduced exposure to exhaust cannot be included in the benefits calculation formula, as the data is not refined enough to allow assigning value to reduced exposure to a specific volume of emissions for a given number of minutes. However, the potential health benefits are substantial for children with breathing problems.

Carbon dioxide threatens the earth's atmosphere by trapping heat. Although the United States has only four percent of the world's population, it consumes about one-fourth of the world's yearly oil production and produces about one-fourth of all carbon dioxide emissions [11][35].

One gallon of gasoline produces 19.564 pounds of $\mathrm{CO}_{2}$, according to the Energy Information Administration [24]. Automobile exhaust contains other greenhouse gases (GHG) which are not included in the calculation formula as they relate more closely to miles driven rather than fuel consumed and because they constitute only five to six percent of GHG, versus $\mathrm{CO}_{2}$, which accounts for 9495 percent of the GHG emitted by tailpipe exhaust [9].

Gasoline and diesel consumption for vehicles depends on fuel economy, which U S automakers have long resisted. For example, five cars with gas mileage over 40 miles per gallon (MPG) could be purchased in 2005 in the U S; only two cars with 40 MPG were available in 2007. In markets outside the U S, 113 cars with over 40 MPG could be purchased in 2007 [4][12].

Federal law mandates Corporate Average Fuel Economy (CAFE), the weighted average miles per gallon of a manufacturer's fleet of passenger cars for sale in the United States in any given model year. Current CAFE standards are 27.5 MPG for passenger cars, a number that has not changed since model year 1984[33]. Actual MPG averages are lower than federal standards. For purposes of this study, 20 MPG will be used to estimate basic fuel economy [3].

\section{Automobile Fuel Consumed While Idling}

Vehicle tailpipe emissions relate directly to gasoline combustion. Running a vehicle at idle speed uses less gas than open road driving, therefore produces less exhaust. Unlike open road driving, however,
Issues in Information Systems 
emissions at idle are disproportionately affected by temperature, accessory load, idle speed, fuel-air mixture, and engine tuning [15].

Many school districts, primarily in metropolitan areas, now ask drivers to turn off vehicles while waiting to pick up children from school [1]. Several states and many municipalities have legal or voluntary restrictions against idling, most frequently for heavy-duty or diesel vehicles [10][17]. The EPA offers the following advice, "You will save gas by turning the engine off and restarting it again if you expect to idle for more than 30 seconds. You will also prevent pollution by avoiding long idles [8].

For purposes of this study, we assume that the average vehicle found in the population of interest reflects the national average of on-road vehicles in 2009 that get 20 MPG and that use about .50 gallons/hour (or 0.00833 gallons/minute) at idle and inefficient low speed driving [2].

\section{Formulae for Fuel Consumption and Carbon Footprint}

The benefits calculation formula for $\mathrm{CO}_{2}$ is:

[X number of vehicles] $\mathrm{x}$ [(wait $\mathrm{Y}$ minutes) $\mathrm{x}(.00833$ gallons/minute $\mathrm{x} 19.6$ pounds of $\mathrm{CO}_{2}$ per gallon) $]=\mathrm{Z}$ pounds of $\mathrm{CO}_{2}$

The benefits calculation formula for fuel expense is:

[X number of vehicles] $\mathrm{x}$ [(wait $\mathrm{Y}$ minutes) $\mathrm{x}(.00833$ gallons/minutes $\mathrm{x} \$ 3.00$ per gallon) $]=\$ \mathrm{Z} . \mathrm{ZZ}$

\section{Using Computer Simulation to Model Traffic Congestion}

Computer simulation is a tool that can be used to model alternative ways to alleviate traffic congestion. The use of computer simulation modeling was a success in 2001 when The National Capital Planning Commission (NCPC) formed an Interagency Security Task Force to examine ways to alleviate traffic congestion. Traffic simulation was used to produce seven different design options [5]. Computer simulation modeling has also been used to simulate varying traffic queues when additional elements are introduced [28].

Simulation modeling can be used predict future traffic patterns and congestion. The Transportation Analysis Simulation System (TRANSIMS) is a complex computer system that uses existing data to predict potential crises. TRANSIMS is sponsored by the Department of Transportation and the Environmental Protection Agency and is aimed at evaluating environmental changes caused by major projects as well as individual choices [36].

\section{Benefits of RFID to Reduce Waiting}

The School-Pass ${ }^{\mathrm{TM}}$ carpool dismissal management system developed by the MHR Technologies, Inc. was implemented in 2005 at St. Elizabeth Catholic School and the National Cathedral Elementary School. According to the information from the company, it was able to help school administrators, staff, and faculty to increase student safety and security, reduce parent wait time by $50-60 \%$, improve dismissal operations, reduce traffic impact on nearby streets, and improve the change management process [21].

\section{METHODOLOGY}

\section{Current System Description}

Figure 1 shows the existing system traffic flow for the elementary school for kindergarten and first grade. Note: Figure 1 is not to scale, and only shows part of the school relevant to this paper. At around 2:50 pm, parents begin arriving to pick up children, and school lets out at 2:55. Parents must enter school grounds from the south on a two lane, one-way street. Parents collecting kindergarteners use the south loop and pickup area \#3. First graders are collected in the north loop in pickups \#1 and \#2, which are teacher specific. If parents have both kindergarteners and older children, the older children are instructed to go to their younger siblings at pickup \#3. 
Figure 1. Current System Layout and Traffic Flow

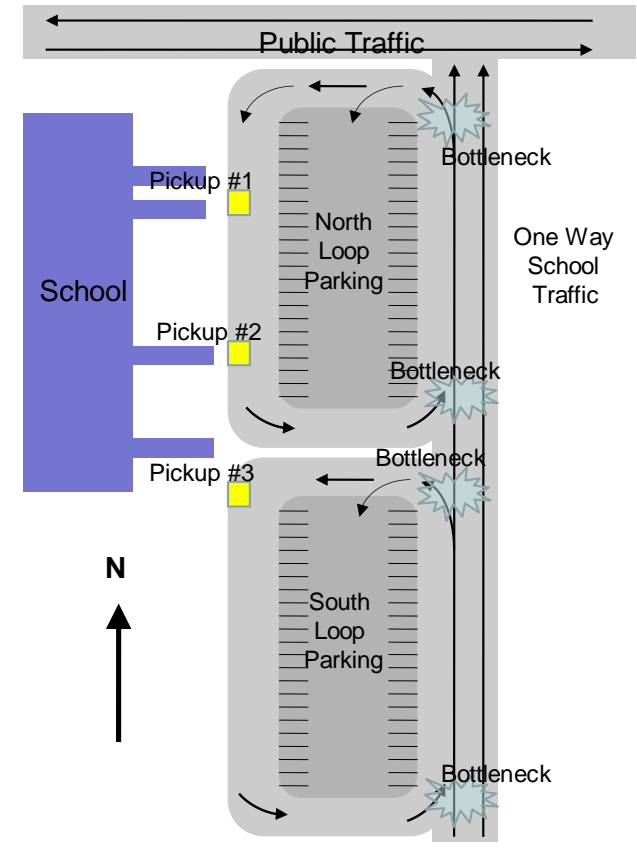

Only one vehicle at a time collects kids at each location. Once collected, parents re-enter the twolane, one-way street, choosing either the left lane or right lane for west bound and east bound public traffic, respectively. Vehicles leaving the school grounds are controlled by a stop sign. As expected, the two-way public traffic lane is busy and restricted to $25 \mathrm{mph}$ during this period. No stop signs or stoplights control public traffic in the area.

About 100 vehicles arrive to collect kids from 2:50 until around 3:15, with a noticeable spike in the arrival rate at 2:55. Teachers supervise children, identifying parents before allowing children to begin loading. City law enforcement officers are occasionally on-site to monitor traffic, usually at the beginning of the school year.
The current design forces parents who have not collected and those who have collected to wait in the same two-lane, one-way traffic. The initial bottleneck, the north bottleneck, appears because of two reasons. The first is that parents stage, arriving prior to students being let out. Once student pickup begins, those that have collected have to wait behind those waiting to collect. The second is waiting to enter public traffic creates queues that affect both those collecting and those who have already collected. The queues lengthen south on the two lane, one-way traffic eventually spilling outside of school grounds.

Currently, the major issues are waiting, pollution and frustration. Only minor traffic accidents have occurred, and no major injuries have been recorded. Interestingly, during data collection, one of the researchers witnessed a minor automobile accident as vehicles continually started and stopped as they inched to collect kids.

\section{Current System Simulation Model Design and Validation}

Table 1 shows the data collection results and the probability distribution goodness-of-fit statistics. Table 2 shows the simulation model validation statistics and results. The three key performance indicators (kpi) are the average time in system for both east bound (556 seconds) and west bound (650 seconds) vehicles and the maximum number of vehicles waiting (62 vehicles) in the loops. For each, twenty days of sampled data was tested against twenty days of simulated data. The null hypothesis was that no difference existed, and the t-tests demonstrated that the base model was valid. Therefore, the current system has up to 60 parents/vehicles waiting at once and the average wait time is 10 minutes, for a system when only 100 kids are being collected! 
Table 1. Data Collection Results

\begin{tabular}{lcc}
\hline \multicolumn{1}{c}{ Description } & Parameters & $\chi \mathbf{2}$ GOF Validation \\
\hline Public Traffic East Bound Rate (Cars/Minute) & Poisson (rate =6.6) & $\chi^{2}=4.8, \mathrm{df}=5, \mathrm{n}=42$ \\
Public Traffic West Bound Rate (Cars/Minute) & Poisson (rate =7.6) & $\chi^{2}=2.6, \mathrm{df}=5, \mathrm{n}=42$ \\
Pickup Time (all locations) & Normal $(\mu=39, \sigma=8)$ & $\chi^{2}=2.6, \mathrm{df}=5, \mathrm{n}=100$ \\
Parent Arrival: 2:55 to 3:00 (Cars/Minute) & Poisson (rate =10/min) & $\chi^{2}=7.6, \mathrm{df}=4, \mathrm{n}=20$ \\
Parent Arrival: 3:00 to 3:05 (Cars/Minute) & Poisson (rate =5/min) & $\chi^{2}=2.6, \mathrm{df}=4, \mathrm{n}=20$ \\
Parent Arrival: 3:05+ (Cars/Minute) & Poisson (rate =1.25/min ) & $\chi^{2}=4.1, \mathrm{df}=4, \mathrm{n}=20$ \\
Average Number of Vehicles & 102 & \\
& & \\
\% Heading West After Pickup (Left Turn) & $45 \%$ \\
\% Heading East After Pickup (Right Turn) & $55 \%$ \\
\% Using Pickup \#1 & $33 \%$ & \\
\% Using Pickup \#2 & $33 \%$ & \\
\% Using Pickup \#3 & $33 \%$ & \\
\hline
\end{tabular}

Table 2. Model Validation Results

\begin{tabular}{lcc}
\hline \multicolumn{1}{c}{ Key Performance Indicator (kpi) } & Validation Test & Conclusion: Fail to Reject \\
\hline West Bound Average TIS (Left Turn) $=650 \mathrm{sec}$ & t-test & $\mathrm{n}_{1}=\mathrm{n}_{2}=20, \mathrm{p}$-value $=0.64$ \\
East Bound Average TIS (Right Turn) $=556 \mathrm{sec}$ & t-test & $\mathrm{n}_{1}=\mathrm{n}_{2}=20, \mathrm{p}$-value $=0.82$ \\
Average Maximum Queue Size $=63$ cars & t-test & $\mathrm{n}_{1}=\mathrm{n}_{2}=20, \mathrm{p}$-value $=0.39$ \\
\hline
\end{tabular}

\section{PROPOSED SYSTEM DESCRIPTION USING} RFID TO REDUCE AFTERSCHOOL PICKUP TIMES

Design solutions began with interviews with local law enforcement, parents and school administration. Many ideas were proposed. Most involved new traffic light systems, which are expensive. However, a common issue discussed was how long it took for kids to load in their parent/guardian's vehicle. The act of loading was no problem (most kids want to go home!); however, identifying vehicles and staging children was often found to be an issue. Vehicle identification is the responsibility of the teacher, who must often rely on the children, who may not be paying attention. The identification act, therefore, was a potential activity that could be attacked. Additionally, demand spiked exactly when school was let out. Sudden demand created queues quickly. Parents that arrived 10 minutes later experienced very little waiting before collecting.

Therefore, a proposed design was tested using two different factors: (1) decreasing the pickup time and (2) smoothing demand. Additionally, two separate experiments were run for two different traffic volumes: 100 and 150 cars. The null hypotheses area shown below:

$\mathrm{H}$ null demand pattern, 100: at 100 cars, mean time-insystem is the same for spiky demand and level demand

Volume XI, No. 1, 2010

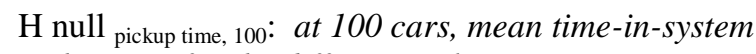
is the same for the different pickup times

$\mathrm{H}$ null demand pattern, 150: at 150 cars, mean time-insystem is the same for spiky demand and level demand

$\mathrm{H}$ null pickup time, 150 : at 150 cars, mean time-in-system is the same for the different pickup times

\section{ANALYSIS}

The proposed design was tested by a simulated experiment and two-factor ANOVA with replication. Two different ANOVA were performed. The first was using the current volume of 100 cars entering the system, following by increasing volume to 150 cars, which would reflect continued population growth. The simulation model was developed with SIMUL8 with a MS Excel interface. MS Excel with its Data Analysis add-in was used to perform the ANOVA.

Figure 2 shows the average time in system (ATIS) with different average pickup times. Based on the validation study, pickup times were assumed to follow a normal distribution. Additionally, the coefficient of variation was assumed to remain constant at 0.20. As expected, as the pickup time decreased, the ATIS also decreased. Recall from Table 1 that the current system has pickup times around 40 seconds. Diminishing returns seem to
Issues in Information Systems 
occur when the pickup times moved from twenty to ten seconds. Additionally, leveling demand also reduced the ATIS for almost all levels of pickup times. Finally, the larger volume of 150 cars negatively impacts the ATIS.

Figure 2. Average Time in System as a Function of Pickup Time and Demand Patterns

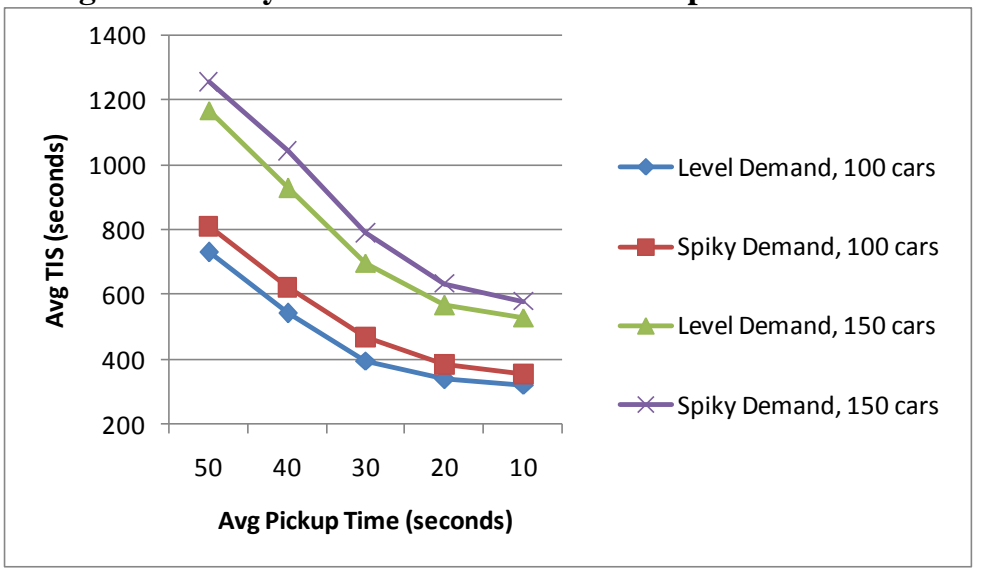

Tables 3 through 6 show the ANOVA tables for the ATIS and maximum number of cars waiting for 100 cars and 150 cars. Both the average pickup time and demand pattern are significant for ATIS and only the average pickup time is significant for the maximum number of cars waiting. No interaction effects occurred in any of the ANOVA.

Table 3. ATIS ANOVA Table: Number of Cars $=100$

\begin{tabular}{lrrrrrr}
\hline \multicolumn{1}{c}{ Source of Variation } & \multicolumn{1}{c}{ SS } & df & \multicolumn{1}{c}{ MS } & \multicolumn{1}{c}{ F } & \multicolumn{1}{c}{ P-value } & F crit \\
\hline Demand Management (spiky vs. level) & 95639 & 1 & 95638.65 & 8.39 & 0.00 & 3.95 \\
Average Pickup Time & 2584804 & 4 & 646200.92 & 56.67 & 0.00 & 2.47 \\
Interaction & 8816 & 4 & 2203.91 & 0.19 & 0.94 & 2.47 \\
Within & 1026311 & 90 & 11403.45 & & & \\
Total & 3715569 & 99 & & & & \\
\hline
\end{tabular}

Table 4. Maximum Number of Cars Waiting ANOVA Table: Number of Cars $=100$

\begin{tabular}{lrrrrrr}
\hline \multicolumn{1}{c}{ Source of Variation } & \multicolumn{1}{c}{ SS } & \multicolumn{1}{c}{ df } & \multicolumn{1}{c}{ MS } & \multicolumn{1}{c}{ F } & \multicolumn{1}{c}{ P-value } & \multicolumn{1}{l}{ F crit } \\
\hline Demand Management (spiky vs. level) & 193 & 1 & 193.21 & 1.42 & 0.24 & 3.95 \\
Average Pickup Time & 9803 & 4 & 2450.74 & 17.97 & 0.00 & 2.47 \\
Interaction & 17 & 4 & 4.34 & 0.03 & 1.00 & 2.47 \\
Within & 12277 & 90 & 136.41 & & & \\
Total & 22291 & 99 & & & & \\
\hline
\end{tabular}

Table 5. ATIS ANOVA Table: Number of Cars $=150$

\begin{tabular}{lrrrrrr}
\hline \multicolumn{1}{c}{ Source of Variation } & \multicolumn{1}{c}{ SS } & \multicolumn{1}{c}{ df } & \multicolumn{1}{c}{ MS } & \multicolumn{1}{c}{ P } & \multicolumn{1}{c}{ P-value } & \multicolumn{1}{l}{ F crit } \\
\hline Demand Management (spiky vs. level) & 163749 & 1 & 163748.69 & 7.75 & 0.01 & 3.95 \\
Average Pickup Time & 6107883 & 4 & 1526970.73 & 72.23 & 0.00 & 2.47 \\
Interaction & 11793 & 4 & 2948.29 & 0.14 & 0.97 & 2.47 \\
Within & 1902542 & 90 & 21139.35 & & & \\
Total & 8185966 & 99 & & & & \\
\hline
\end{tabular}


Table 6. Maximum Number of Cars Waiting ANOVA Table: Number of Cars $=150$

\begin{tabular}{lrrrrrr}
\hline \multicolumn{1}{c}{ Source of Variation } & \multicolumn{1}{c}{ SS } & \multicolumn{1}{c}{ df } & \multicolumn{1}{c}{ MS } & \multicolumn{1}{c}{ F } & \multicolumn{1}{c}{ P-value } & \multicolumn{1}{l}{ F crit } \\
\hline Demand Management (spiky vs. level) & 130 & 1 & 129.96 & 0.48 & 0.49 & 3.95 \\
Average Pickup Time & 17335 & 4 & 4333.87 & 16.02 & 0.00 & 2.47 \\
Interaction & 23 & 4 & 5.69 & 0.02 & 1.00 & 2.47 \\
Within & 24352 & 90 & 270.58 & & & \\
Total & 41840 & 99 & & & & \\
\hline
\end{tabular}

Table 7 show the benefits of the proposed system with level demand for a range of pickup times and number of vehicles against the current system of a forty second pickup time and spiky demand.

Table 7. Benefits of the Proposed System vs. Current System

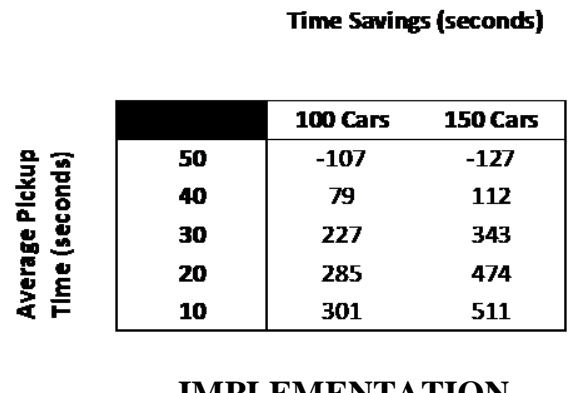

IMPLEMENTATION

The proposed RFID networked system consists of two RFID readers, RFID tags, a computer system, a database server, a web server, and LCD monitors, as shown in Figure 3. RFID tags are located on the windshield of the parent/guardian's vehicle. One RFID reader will scan parent arrivals at the school's south entrance area; thus, identification occurs prior to the parents entering any pickup area, reducing pickup time. The unique tag ID is then sent through the network to the main computer system in the Data Center to verify the parents against the ParentsStudents Database. Once verified, the system will display the parent-student photos in the order of their parents' arrival sequence over all the LCD monitors, which are located at the pickup locations. Teachers can sequence students according to the information from the LCD monitors. Sequencing speeds up the pickup process by reducing out-of-order student waiting, which is common for students who want to be the first in line. The second RFID reader will be installed at the north exit. Once an RFID tag is scanned, the computer system will log the exit time and remove the parent-student photos from the LCD monitors.

Volume XI, No. 1, 2010
Annual Fuel Savings (\$)

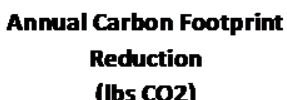

\begin{tabular}{|cc|}
\hline 100 Cars & 150 Cars \\
\hline$-\$ 444$ & $-\$ 794$ \\
$\$ 330$ & $\$ 701$ \\
$\$ 945$ & $\$ 2,143$ \\
$\$ 1,187$ & $\$ 2,960$ \\
$\$ 1,254$ & $\$ 3,195$ \\
\hline
\end{tabular}

\begin{tabular}{|cc|}
\hline 100 Cars & 150 Cars \\
\hline$-8,699$ & $-15,560$ \\
6,478 & 13,731 \\
18,516 & 41,996 \\
23,269 & 58,007 \\
24,570 & 62,621 \\
\hline
\end{tabular}

Figure 3. The RFID Networked System

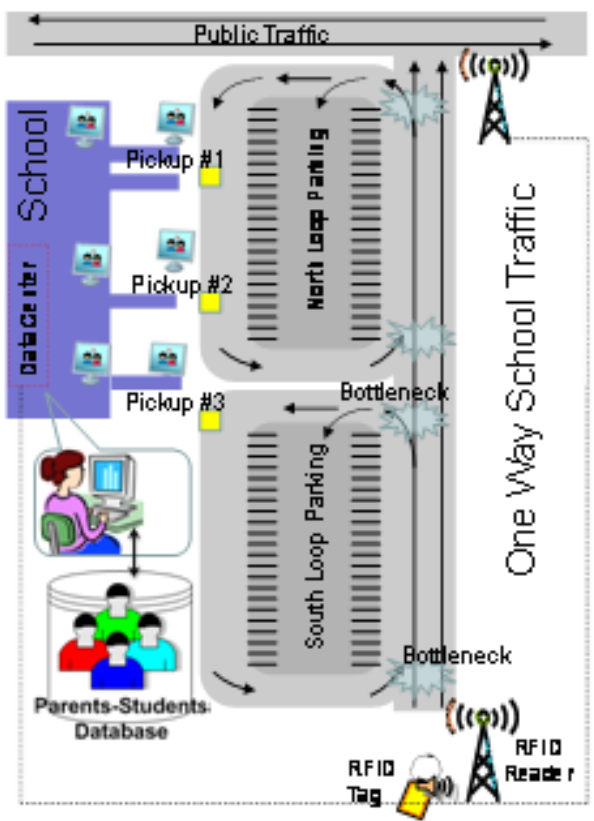

Readers and tags cost $\$ 1500$ and $\$ 10$, respectively. The estimated initial cost of the proposed RFID system is estimated to be $\$ 14,300$. Based solely on fuel savings, costs outweigh benefits; however, other benefits exist such as increased productivity, less pollution, increased safety and security, less frustration, and fewer accidents. 


\section{CONCLUSION}

In this paper, we used discrete-event simulation (DES) to model the benefits of RFID to reduce traffic congestion at an afterschool pickup site. RFID reducing pickup times and demand management policies that converted spiky demand into level demand were found to significantly reduce ATIS. At the rural Oklahoma school used in the study, reducing pickup times by twenty seconds could save around three thousand dollars annually in fuel costs and could reduce the school's annual carbon footprint by up to 58 thousand pounds of carbon dioxide.

Although more difficult to quantify, the proposed RFID system also increases safety and security. The proposed system has the potential to reduce accidents by reducing parents' frustration due to waiting. Further, the primary security advantage of the proposed RFID system is to verify that the adults who arrive to pick up children have the authority to do so. The display of the parent-student photos over the LCD monitor helps teachers easily identify and recognize the faces of parents or guardians.

\section{REFERENCES}

1. Babcock, K. (January 22, 2008). "Program aims to reduce emissions, promote health", McClatchy - Tribune Business News, Washington.

2. Burgess, E., Peffers, M., Silverman, I., (2009). "Idling Gets You Nowhere, the Health Environmental, and Economic impacts of Engine Idling”, research sponsored by the Environmental Defense Fund, retrieved August 9, 2009 from http://www.edf.org/documents/9236_Idling_No where 2009.pdf.

3. Clean Vehicles (2009). "The Plain English Guide to Tailpipe Standard", Union of Concerned Scientists, retrieved July 7, 2009 from http://www.ucsusa.org/clean_vehicles/vehicle_i mpacts/cars_pickups_and_suvs/the-plainenglish-guide-to.html

4. Civil Society Institute (2007). CSI/40MPG.org: 'Fuel-Efficient Car Gap' Growing as U.S. Falls to Two 40MPG+ Vehicles, While Number of GasSipping Cars Unavailable in U.S. Rises to Well Over 100; Survey: Over 2.5 Million Americans Want Fuel-Efficient Vehicles ... But Have Been Frustrated; Four Out of Five Want Fuel-Efficient Vehicles Now Off Limits to Them, Seek Hill
Action. PR Newswire, Retrieved July 7, 2009, from ABI/INFORM Dateline.

5. Dittberner, R. A., \& Kerns, R. T. (2002). Past President's Award Paper: Traffic simulation in congested urban networks: Pennsylvania Avenue case study. Institute of Transportation Engineers, 36-42.

6. Ebbesen, E., and Haney, M. (1973). "Flirting with Death: Variables Affecting Risk Taking at Intersections", Journal of Applied Social Psychology, 3(4): 303 - 324.

7. Edwards J, Walters S, and Griffiths R K. (1994). Hospital admissions for asthma in preschool children: relationship to major roads in Birmingham, United Kingdom. Arch Environ Health 1994; 49(4):223-7.

8. EPA (Environmental Protection Agency) Consumer, "Your Car and Clean Air: What YOU Can Do to Reduce Pollution", retrieved August 11, 2009 from http://www.epa.gov/otaq/consumer/18youdo.pdf

9. EPA- OTAG (2005). "Emission Facts: Greenhouse Gas Emissions from a Typical Passenger Vehicle", retrieved August 9, 2009 from http://www.epa.gov/otaq/climate/420f05004.htm

10. EPA - New England, (2002) "What You Should Know about Diesel Exhaust and School Bus Idling", retrieved August 9, 2009 fromhttp://www.maine.gov/dep/air/school/Diesel _Factsheet_Schoolbus.pdf

11. Feinstein, D., (2007). Global Warming, Vital Speeches of the Day, 73(1), 16-19, retrieved February 22, 2009, from ABI/INFORM Global database.

12. Gas Mileage Gap, Anonymous, (2007). "The Europeans, Japanese and Chinese are already committed to far more aggressive MPG standards than we are in the United States", Multinational Monitor, Washington, Vol. 28, Iss. $1 ;$ pg. 5

13. Gilliland, F.D. (2009). "Outdoor Air Pollution, Genetic Susceptibility, and Asthma Management: Opportunities for Intervention to Reduce the Burden of Asthma", Pediatrics, Vol.123, supplement, p. S168-S173.

14. Henderson, R., (2006). "Carbon dioxide measures up as a real hazard", Occupational Health \& Safety, 75(7), 64, 68-69. Retrieved July 8, 2009, from ABI/INFORM Global.

15. Hilliard, J.C., Springer, G. S., Editors, (1984). Fuel Economy in Road Vehicle Powered by Spark Ignition Engines, General Motors Symposia Series, Plenum Press, NY, NY. 
16. Horng, G-J., Horng, C-F., and Jong, G-J. (2007). "Mobile RFID of Wireless Mesh Network for Intelligent Safety Care System", Proceedings of the World congress on Engineering and Computer Science 2007, WCECS 2007, Oct. 2426, San Francisco, USA.

17. Idling Restrictions- "New Diesel Vehicle Idling Restrictions Will Keep Air Cleaner, Reduce Fuel Consumption" (2009). PR Newswire, retrieved February 16, 2009, from ABI/INFORM Dateline database.

18. Kim, J. J., Smorodinsky, S., Lipsett, M., Singer, B.C., Hodgson, A. T., Ostro, B. (2004). "Trafficrelated air pollution near busy roads: the East Bay Children's Respiratory Health Study", American Journal of Respiratory and Critical Care Medicine, Vol 170, 520-526.

19. Landt, Jerry (2001). "Shrouds of Time: The history of RFID" (PDF). AIM, Inc.. http://www.transcore.com/pdf/AIM\%20shrouds_ of_time.pdf. Retrieved 2006-05-31.

20. Li, X. and Ranga, U.K. (2009). "Design and Implementation of a Digital Parking Lot Management System", the 2009 Technology Interface Journal, Fall 2009.

21. MHR Technologies, The School-Pass ${ }^{\mathrm{TM}}$ system, Rockville, Maryland. http://www.mhrtechnologies.com/, retrieved April 12, 2010.

22. Naik, G., (2007). "Global Warming May Be Spurring Allergy, Asthma; Dr. Ziska's Ragweed Loves Carbon Dioxide; Toxic Pollen in Cities?" Wall Street Journal (Eastern Edition), A.1. Retrieved July 7, 2009, from ABI/INFORM Global.

23. National Association of Physicians for the Environment, Air Pollution: Impacts on Body Organs and Systems conference (1994). "Automotive Exhaust Chemicals: disease causing effects", retrieved August 9, 2009 from http://www.nutramed.com/environment/carsche micals.htm

24. Official Energy Statistics (2008). Fuel and Energy Source Codes and Emission Coefficients, Energy Information Administration, Department of Energy, retrieved July 7, 2009 from http://www.eia.doe.gov/oiaf/1605/coefficients.ht $\mathrm{ml}$

25. Peters, J. M., Avon, E., Naidu, W., London, S. J., Gauderman, W. J., Lurmann, F., Linn, W. S., Margolis, H., Rappaport, E., Gong, H., et. al. (1999). "A study of twelve Southern California communities with differing levels and types of air pollution", American Journal of Respiratory Critical Care Medicine, 159(3), 760-7.
26. Radio-frequency 3/28/2010.

27. Reese, M., (2009). Arizona State University study, Pollution aggravates children's asthma symptoms, "Valley has had elevated levels of particulate matter this week", McClatchy Tribune Business News, retrieved February 16, 2009, from ABI/INFORM Dateline database.

28. Roberg, P., \& Christopher, A. R. (1998). Diagnosis and Treatment of Congestion in Central Urban Areas. European Journal of Operational Research, 218-230.

29. Rosenlund, M., Forastiere, F., Porta, D., DeSario, M., Badaloni, C. Perucci, C.A. (2009). "Traffic-related air pollution in relation to respiratory symptoms, allergic sensitization and lung function in schoolchildren", Thorax, 64:573-580.

30. The RFID Ecosystem Project - University of Washington, retrieved 3/29/2010, from http://rfid.cs.washington.edu/

31. Singer, B.C., Hodgson, A. T., Hotchi, T., and Kim J. J., (2004). "Passive measurement of nitrogen oxides to assess traffic-related pollutant exposure for the East Bay Children's Respiratory Health Study", Atmospheric Environment, 38(3), 393-403.

32. Sweeney, P. (2005). RFID FOR DUMMIES, Wiley Publishing, Inc.

33. Title 49, United States Code, Subtitle VI. Motor Vehicle and Driver Programs, Part C Information, Standards, and Requirements, Chapters 321, 323, 325, 327, 329, and 331, U.S. Department of Transportation, National Highway Traffic Safety Administration, Office of Chief Counsel, retrieved August 1, 2009 from http://www.nhtsa.dot.gov/nhtsa/Cfc_title49/ACT chap321-331.html

34. Wjst, M., Reitmeir, P., Dold, S., Wulff, A., Nicolai, T., von Loeffelholz-Colberg, E. F., and von Mutius, E., (1993). "Road traffic and adverse effects on respiratory health in children", British Medical Journal, 307(6904), 596-600, retrieved August 8, 2009 from ttp://www.pubmedcentral.nih.gov/articlerender.f cgi?artid=1678953

35. Woolf, M., Brown, (2005). "Beckett Exposes G8 Rift on Global Warming: The US Contribution in Figures", Independent/UK, retrieved August 9, 2009

from http://www.commondreams.org/headlines05/061 3-02.htm

36. Wormser, L. (1997). Travel A La Mode. Planning, 10-14. 
37. Zoghi, B., Singhal, R., Fink, R., and Jung, Y-K. (2006). "RFID Solutions: Parking Optimization and customer Satisfaction", Proceedings of the 2006 IJME-INTERTECH Conference. 